\title{
O ANALFABETISMO NO BRASIL SOB ENFOQUE DEMOGRÁFICO
}

\author{
MARCELO MEDEIROS COELHO DE SOUZA \\ Pesquisador do IPEA
}

\begin{abstract}
RESUMO
O artigo discute algumas relações entre dinâmica demográfica e nível educacional da população a partir do indicador taxa de analfabetismo. Demonstra-se que a evolução das taxas totais de analfabetismo no tempo depende tanto da estrutura etária da população quanto da capacidade do sistema de ensino de alfabetizar indivíduos em todas as idades. Com base na análise de projeções das taxas futuras de analfabetismo até 2020 conclui-se que a velocidade atual de crescimento da alfabetização total é baixa e que seu aumento depende de medidas relacionas à educação de jovens e adultos.

ANALFABETISMO - DADOSESTATÍSTICOS - BRASIL - DEMOGRAFIA
\end{abstract}

\begin{abstract}
LITERACY IN BRAZIL FROMADEMOGRAPHIC PERSPECTIVE. The artide discusses some of the relationships between demographic dynamics and the Population's educational level, using the literacy rate as a basis. It demonstrates that the evolution of total literacy rates over time depends on the age groupings within the population and the capacity of the educational system to form literate individuals at all levels. Based on an analysis of literacy rate projections up to the year 2020, it concludes that the present rate of growth is slow and that an increase depends on taking measures related to education for adults and youth.
\end{abstract}


Diversos estudos ressaltam o baixo nível educacional atual da população brasileira. Há um consenso praticamente generalizado de que esse nível, por várias razões, deve ser elevado o mais rápido possível. Nesse sentido, analistas de políticas de educação básica têm enfatizado a necessidade do aumento na cobertura escolar da população de sete a quatorze anos e de melhorias na qualidade do ensino ministrado no Brasil. Essa ênfase tem resultado em políticas orientadas especialmente à população convencionada como em "idade escolar". Pouca atenção tem sido dada ao ensino básico de grupos fora dessa idade convencionada.

Adotando um indicador dos primeiros resultados do ensino básico, a alfabetização, o artigo discute algumas relações entre a dinâmica demográfica e o nível educacional da população. Por serem registrados nos censos desde pelo menos o início deste século, dados sobre alfabetização permitem uma visão geral das mudanças no perfil educacional da população em um prazo relativamente longo, facilitando inferências do ponto de vista demográfico. Estas, por sua vez, são um elemento importante no debate sobre condições educacionais da população brasileira.

Como indicador, a taxa de alfabetização não se limita a sintetizar a capacidade média de acesso à cultura escrita, podendo também representar o perfil educacional básico de uma população, pois o aprendizado da escrita ocorre simultaneamente ao aprendizado de outras habilidades intelectuais (Soares, 1985. p.21-3, Rockwell, 1985. p.86). Diferente das medidas de escolarização, que representam a abrangência do ensino escolar em determinado momento do tempo, ou seja, um processo, a taxa de alfabetização reflete um produto, a educação propriamente dita.

O nível educacional a que a alfabetização se refere é pequeno. O recorte entre alfabetizados e analfabetos fornece informações muito elementares sobre uma população. Reconhecendo a complexidade das demandas da sociedade contemporânea sobre as habilidades de leitura e escrita, pesquisadores têm, nas últimas duas décadas, desviado seu o interesse pelo fenômeno do analfabetismo absoluto, determinado pela incapacidade de ler (ou ler e escrever) textos simples, para o chamado analfabetismo funcional, que compreende não só a leitura e compreensão de textos em prosa (como mensagens, notícias e instruções) como também o uso de textos de informação esquemática e numérica (como tabelas e gráficos), bem como habilidades de escrita e cálculo para fins pragmáticos em contextos cotidianos, domésticos ou de trabalho. Mais recentemente, têm sido utilizados os conceitos de literacy (alfabetismo ou letramento) e numeracy (domínio do cálculo) no lugar de analfabetismo funcional, com o objetivo de melhor classificar os indivíduos que não compõem o grupo de analfabetos absolutos.

movimento de ampliação do campo de pesquisa para além do analfabetismo absoluto não deve, no entanto, ser visto como antagônico à sua utilização como indicador. No caso de sociedades com nível educacional elevado, as taxas de analfabetismo podem oferecer informações restritas; para o Brasil, no entanto, onde o nível educacional da população é notoriamente baixo, trata-se de um instrumento útil para a avaliação direta da distribuição de 
educação básica em grandes populações, tarefa difícil de ser realizada através de testes de determinação do analfabetismo funcional. Apesar de suas limitações, a taxa de alfabetização é um indicador amplo que, além de considerar os resultados da educação escolar, inclui os resultados da educação não escolar (como o aprendizado doméstico, no trabalho, etc.). Além disso, no caso de análises de longos períodos de tempo por meio de cortes censitários decenais, a taxa de alfabetização representa um estoque acumulado no tempo que, ao contrário de, por exemplo, taxas de escolarização, é pouco sensível a flutuações nas datas de recenseamento.

Com base em dados agregados para o Brasil, discute-se a elevação das taxas de alfabetização a partir do início deste século, mostrando que, mesmo com as melhorias, o Brasil ainda ocupa uma posição inferior na comparação com outros países. Demonstra-se que as taxas totais de analfabetismo dependem da estrutura etária da população e da capacidade do sistema de ensino de alfabetizar indivíduos em todas as faixas. A partir de algumas hipóteses, são realizadas projeções das taxas futuras de analfabetismo, as quais sugerem que a velocidade de crescimento da alfabetização total é ainda baixa para colocar, nas próximas décadas, o Brasil em pé de igualdade com outros países.

Supondo mudanças radicais no contexto atual do analfabetismo no Brasil, é discutida a viabilidade de execução de algumas das metas do Plano Nacional de Educação, dentro do prazo de dez anos estabelecido pela Lei de Diretrizes e Bases da Educação Nacional. Mostrase que mesmo metas menos rigorosas envolvem esforços significativos para seu cumprimento em um prazo tão restrito.

Deve-se ter ressalvada a maneira como educação é tratada neste trabalho. Discutir se o aumento da alfabetização é ou não uma melhoria é, obviamente, discutir sobre um juízo de valor. Todavia, a posição, em relação à educação básica, que permite considerar aumentos na alfabetização como sendo positivos, é praticamente consensual. $\bigcirc$ artigo sustenta essa posição e, assim, realiza comparações e define algumas hipóteses e conclusões em termos valorativos.

\section{EVOLUÇÃO DAS TAXAS DE ALFABETIZAÇÃO}

A tabela I mostra as taxas de alfabetização da população brasileira de quinze ou mais anos de idade a partir de 1920. Ainda que os critérios para a definição de um "alfabetizado" não tenham sido os mesmos ao longo dos anos', é possível observar que a proporção dos que se consideravam alfabetizados no país, entre 1900 e 1991, foi mais do que duplicada.

A partir de 1920 as proporções de alfabetizados da população têm crescido de maneira estável. Da metade deste século em diante, a população mostra crescimento acelerado, mas o volume de analfabetos se mantém relativamente constante, o que resulta em

I. O critério atual do FIBGE para definir alfabetizado é a habilidade de escrever um bilhete simples. 
aumento nas taxas de alfabetização. A constância desse volume, em parte, pode ser explicada pela manutenção dos analfabetos de gerações passadas na população. Quando o ensino, especialmente o escolar, focaliza quase que exclusivamente a população jovem, torna-se, após certa idade, difícil aos adultos reverter sua condição de analfabeto. Assim, o envelhecimento de uma geração de analfabetos pode, nesse caso, ser considerado o componente demográfico da manutenção do analfabetismo. Entretanto, para ser mantido no tempo, o estoque de analfabetos exige reposição, ou seja, o surgimento de novos analfabetos nas gerações mais novas. Logo, além dos aspectos essencialmente relacionados à dinâmica demográfica, o analfabetismo está também relacionado a condições que "produzem" novos analfabetos.

\section{TABELA I}

ALFABETIZAÇÃO DA POPULAÇÃO DE I5 ANOS E MAIS - BRASIL 1900-199।

\begin{tabular}{llrcc}
\hline Ano & Alfabetizados & Analfabetos & Sem Declaração & Taxa de Alfabetização \\
\hline 1900 & 3.380 .451 & 6.348 .869 & $22.79 \mid$ & $35 \%$ \\
1920 & 6.155 .567 & 11.401 .715 & - & $35 \%$ \\
1940 & 10.379 .990 & 13.269 .381 & 60.398 & $44 \%$ \\
1950 & 14.916 .779 & 15.272 .632 & 60.012 & $49 \%$ \\
1960 & 24.259 .284 & 15.964 .852 & 54.466 & $60 \%$ \\
1970 & 35.586 .771 & 18.146 .977 & 274.856 & $66 \%$ \\
1980 & 54.793 .268 & 18.716 .847 & 31.828 & $75 \%$ \\
1991 & 76.603 .804 & 19.233 .239 & - & $80 \%$ \\
\hline
\end{tabular}

Fonte: FIBGE, 1995.

As taxas de analfabetismo do Brasil são altas, se comparadas com as de outros países. A tabela 2 ilustra a posição do Brasil e regiões entre países selecionados em anos próximos a 1990². Enquanto diversos países que não podem ser considerados altamente desenvolvidos têm taxas de analfabetismo abaixo dos 6\%, o Brasil apresenta taxas de 18\%, ficando, na América Latina, em uma posição intermediária entre Equador e Bolívia.

TABELA 2

TAXAS DE ANALFABETISMO, POPULAÇĀO DE I5 OU MAIS ANOS EM PAÍSES SELECIONADOS - 1990

\begin{tabular}{llc}
\hline & País & Analfabetismo \\
\hline Bulgária & $2 \%$ \\
Espanha & $3 \%$ \\
Argentina & $4 \%$ \\
Chile & $6 \%$ \\
Cuba & $6 \%$ \\
Israel & $6 \%$ \\
Paraguai & $10 \%$ \\
Equador & $12 \%$ \\
Brasil & $18 \%$ \\
Bolívia & $20 \%$ \\
\hline
\end{tabular}

Fonte: UNESCO, 1994.

2. Nem todos os dados da base da UNESCO, utilizada na tabela 2, correspondem ao ano de 1990. Todavia, a diferença de períodos entre países nunca ultrapassa dois anos. 
A tabela 2 apresenta uma situação estática. Como as taxas totais de analfabetismo possuem um componente demográfico, a história da redução do analfabetismo pode afetar a interpretação dessa situação. Países que iniciaram a redução do analfabetismo mais cedo reduziram o efeito da componente demográfica nas taxas atuais, que tendem a ser menores. Isso permitiria levantar a hipótese de que a má posição do Brasil em relação a países próximos seria resultado de um processo tardio de redução do analfabetismo. Seria possível, inclusive, argumentar que o analfabetismo no Brasil, hoje, é restrito às gerações antigas e, portanto, é meramente uma questão demográfica.

No entanto, a distribuição etária da população analfabeta apresentada no gráfico I não corrobora a hipótese da redução tardia. Se essa hipótese fosse verdadeira, era de se esperar que a estrutura etária da população de analfabetos apresentasse o formato aproximado de uma pirâmide invertida ou de uma ogiva de base estreita. $\bigcirc$ que ocorre, entretanto, é que a distribuição apresenta-se bastante uniforme para o Brasil como um todo. ${ }^{3}$ Os dados da tabela I também apresentam evidência contrária a essa hipótese. No caso de uma redução tardia, em algum momento nos últimos trinta ou quarenta anos - período que englobaria a alfabetização da geração hoje com idades entre quarenta e sessenta anos, aproximadamente - deveria haver uma súbita aceleração na evolução das taxas de alfabetização. No entanto, observa-se um aumento estável da alfabetização a partir de 1920. Isso sugere que não se trata fundamentalmente de uma defasagem, mas sim de uma redução insuficiente do analfabetismo ao longo do tempo. Essa característica na evolução da alfabetização no Brasil indica que o problema não é apenas uma questão demográfica.

\section{GRÁFICO I \\ DISTRIBUIÇÃO ETÁRIA DA POPULAÇÃO ANALFABETA - BRASIL 1996}

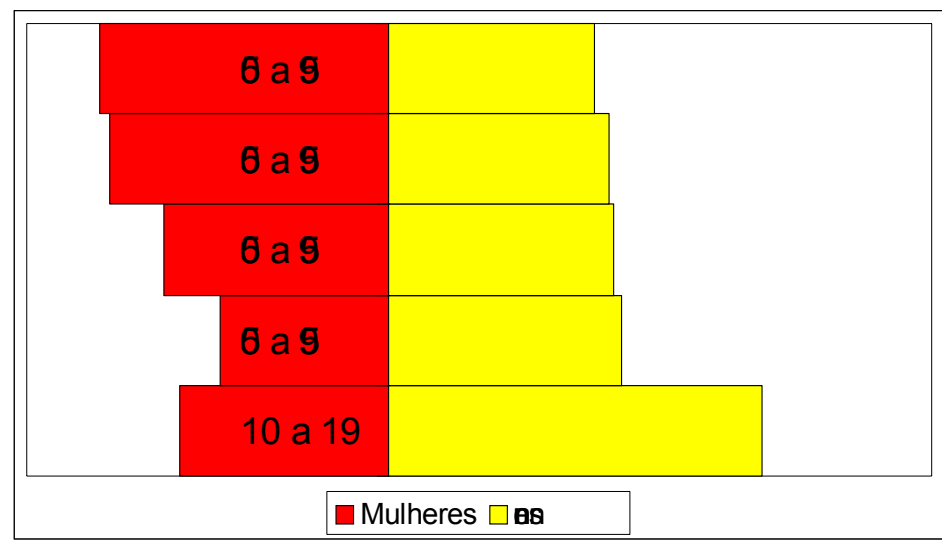

Fonte: FIBGE, 1996.

3. Sabe-se, no entanto, que esses formatos são fortemente diferenciados por região. 
$\bigcirc$ argumento de que as atuais taxas de analfabetismo no Brasil são ainda elevadas apenas por reflexo da insuficiência do sistema de ensino das décadas passadas pode ser derivado da hipótese da redução tardia e já foi objeto de críticas por Ferrari (1985. p.49) e Paiva (1994. p.34). A primeira parte do argumento baseia-se na idéia de que o analfabetismo seria ainda alto porque as pessoas de gerações antigas que permaneceram alheias ao sistema de ensino constituem um estoque de analfabetos que não é alcançado pelos esforços de melhoria do sistema. A segunda parte considera que, com as melhorias do sistema permitindo a redução do analfabetismo nas novas gerações, o estoque de analfabetos será consumido, sem reposição suficiente, com o envelhecimento e morte dos analfabetos e, portanto, a taxa total de analfabetismo cairá.

Na tabela 3 são apresentadas as taxas de analfabetismo, segundo as faixas etárias e a participação da população de cada faixa etária na população total. É possível notar que entre 1980 e 199| houve um deslocamento do peso na determinação da taxa total das gerações mais jovens para as mais velhas. Cresceram as desigualdades na distribuição etária dos analfabetos, aumentando a participação das faixas etárias mais velhas na taxa total de analfabetismo. No entanto, como o analfabetismo atual é também resultado de redução insuficiente ao longo do tempo, as gerações antigas não podem ser consideradas as únicas responsáveis pelas altas taxas atuais, já que pessoas com menos de trinta anos em 1991 determinavam cerca de $31 \%$ do analfabetismo total. Em outras palavras, o estoque de analfabetos na população é, por um lado, consumido pela morte dos analfabetos mais velhos e, por outro, reposto pela não alfabetização de parte da população jovem.

TABELA 3

TAXAS DE ANALFABETISMO SEGUNDO FAIXAS ETÁRIAS

\begin{tabular}{c|c|c|c|c}
\hline & \multicolumn{2}{|c|}{ Taxas de Analfabetismo } & \multicolumn{2}{c}{ Participação no Total } \\
\hline IDADE & 1980 & 1991 & 1980 & 1991 \\
I0 a 19 & $21 \%$ & $15 \%$ & $28 \%$ & $24 \%$ \\
20 a 29 & $17 \%$ & $12 \%$ & $17 \%$ & $16 \%$ \\
30 a 39 & $24 \%$ & $15 \%$ & $16 \%$ & $16 \%$ \\
40 a 49 & $31 \%$ & $24 \%$ & $15 \%$ & $17 \%$ \\
50 a 59 & $37 \%$ & $31 \%$ & $13 \%$ & $15 \%$ \\
60 a 69 & $47 \%$ & $40 \%$ & $10 \%$ & $13 \%$ \\
10 a 69 & $24 \%$ & $18 \%$ & $100 \%$ & $100 \%$ \\
\hline
\end{tabular}

Fonte: FIBGE, 1995.

Em uma estrutura como essa, em que as coortes mais velhas têm taxas de analfabetismo mais altas, a própria dinâmica de renovação da população tende a reduzir a taxa total com a saída dos idosos analfabetos. Isso deve ocorrer mesmo se forem confirmadas as expectativas de redução no número absoluto de jovens esperada para o futuro em razão da queda nas taxas de fecundidade observada nas últimas décadas. Um menor número de jovens nos próximos anos implica maior peso relativo dos mais velhos nas taxas de analfabetismo 
total. Porém, a diminuiç̧ão projetada no número de jovens não será suficiente para anular o efeito da saída dos mais velhos da população.

Para discutir a idéia de que as gerações antigas são pouco atingidas pelas melhorias do sistema de ensino, uma estimativa aproximada da taxa de superação do analfabetismo entre 1980 e 1990 para cada coorte é apresentada na tabela 4. A taxa de superação foi estimada da seguinte forma: em primeiro lugar, foi calculada a proporção da população total mantida na coorte entre uma década e outra, ou seja, a relação entre o número de pessoas contabilizadas em 1990 e o número de pessoas em 1980. O tamanho da coorte em 1990 foi obtido a partir da interpolação geométrica dos dados censitários de 1980 e 1991. A diferença entre os tamanhos de coorte de 1980 e 1990 foi considerada "saída da coorte", por mortalidade, migração ou qualquer outro motivo. Em seguida, o cálculo define que os analfabetos podem deixar a população pelos mesmos motivos que provocam a saída na população total ou pela superação do analfabetismo. Assume que as probabilidades de saída da população analfabeta entre as décadas, excluindo a superação, são as mesmas da população total. Logo, a população que superou o analfabetismo é igual à população analfabeta esperada, caso não houvesse superação, menos a população que se manteve analfabeta observada. A taxa de superação do analfabetismo é obtida pela razão entre a população analfabeta que superou o analfabetismo no fim do período e a população analfabeta total no início do período. No caso de resultados negativos, as taxas de superação são tratadas como sendo iguais a zero (ver Apêndice).

É possível observar que a taxa de superação cai muito com a idade, tornando-se próxima de zero a partir dos trinta anos, corroborando a idéia de que as gerações antigas foram pouco atingidas pelas melhorias do sistema de ensino ocorridas até 1990. Nas circunstâncias observadas entre 1980 e 1990, as chances de mudança na condição de alfabetização dos adultos eram muito pequenas e não há razões aparentes para se crer que esse panorama tenha sofrido alterações significativas ao longo da década de 1990, apesar de estudos já haverem indicado a importância e a urgência de uma política de educação básica para jovens e adultos (Paiva, 1994).

TABELA 4

PROPORÇÕES DAS POPULAÇÕES TOTAL E DE ANALFABETOS MANTIDAS NAS COORTES, E TAXA DE SUPERAÇÃO DO ANALFABETISMO POR FAIXA ETÁRIA, BRASIL 1980-1990

\begin{tabular}{cccl}
\hline GRUPOS DE IDADE & Pop Total Mantida & Pop Analf Mantida & Taxa de Superação \\
\hline I0 a 19 & 0,92 & 0,54 & $41 \%$ \\
20 a 29 & 0,95 & 0,87 & $08 \%$ \\
30 a 39 & 0,97 & 0,96 & $01 \%$ \\
40 a 49 & 0,89 & 0,90 & $0 \% *$ \\
50 a 59 & 0,86 & 0,91 & $0 \% *$ \\
\hline
\end{tabular}

* Taxas de superação foram consideradas nulas. Fonte: FIBGE, 1995. 
Tudo indica que a dinâmica demográfica agirá no sentido de reduzir as taxas de analfabetismo. A questão que se coloca é para quanto e quando. Como há reposição do estoque de analfabetos na população, é de se esperar que apenas a dinâmica demográfica seja insuficiente para promover a redução a níveis razoáveis nos próximos anos. Por isso, para acelerar a redução do analfabetismo, é necessário agir ativamente, tanto sobre o estoque existente, quanto sobre as futuras gerações. Como a reposição se dá pelas gerações mais novas, quanto mais demorar essa ação, por mais tempo perdurará o analfabetismo, mantidas as taxas de superação constantes.

As tabelas 5 e 6 correspondem a dois cenários, um "pessimista" e um "otimista", construídos para analisar simultaneamente o efeito demográfico e o efeito de "produção" de analfabetos na queda do analfabetismo. Eles não representam os limites máximo e mínimo esperados para as taxas de analfabetismo no futuro uma vez que, além de ser possível que diversos fatores não considerados na projeção afetem os níveis futuros de alfabetização da população, o modelo usado não fornece resultados precisos. Mais do que pretender exatidão nas estimativas, os cenários construídos são um instrumento para discutir a importância da educação entre grupos de maior idade.

Em ambos os cenários as populações total e de analfabetos de 1980 e 1991, base das projeções, foram obtidas por dados censitários. A população total em 1990 foi estimada por interpolação geométrica e a de analfabetos pela aplicação das taxas por coorte de |99|, nos valores de 1990, portanto, antecipando em um ano a redução do analfabetismo. As populações totais de 2000 a 2020 foram projetadas pelo IPEA. Para se calcular as populações analfabetas nesses anos, aplicou-se a probabilidade de saída da população analfabeta entre 1980- 1990 nos movimentos de propagação das coortes de analfabetos ao longo do tempo, exceto na primeira coorte. Evidentemente essa aplicação compromete a precisão das estimativas, porque assume como invariantes as probabilidades de superação do analfabetismo. Não é difícil tratá-las como dinâmicas, mas, para o efeito ilustrativo esperado com a montagem dos cenários, a abordagem estática pareceu suficiente. No caso da primeira coorte foram realizadas hipóteses acerca da melhoria nas taxas de alfabetização que resultaram na montagem de dois cenários, o "pessimista", em que a redução é desacelerada no tempo e o "otimista", no qual a redução é constante.

\section{TABELA 5}

\section{CENÁRIO DE REDUÇÃO DESACELERADA}

TAXAS DE ANALFABETISMO - PROJEÇÃO EXPONENCIAL - BRASIL 1980-2020

\begin{tabular}{ccccccc}
\hline IDADE & 1980 & 1990 & $|99|$ & 2000 & 2010 & 2020 \\
\hline I0 a 19 & 0,21 & 0,15 & 0,15 & 0,08 & 0,05 & 0,04 \\
20 a 29 & 0,17 & 0,12 & 0,12 & 0,09 & 0,04 & 0,03 \\
30 a 39 & 0,24 & 0,15 & 0,15 & 0,11 & 0,08 & 0,04 \\
40 a 49 & 0,31 & 0,24 & 0,24 & 0,15 & 0,11 & 0,08 \\
50 a 59 & 0,37 & 0,31 & 0,31 & 0,24 & 0,15 & 0,11 \\
60 a 69 & 0,47 & 0,40 & 0,40 & 0,33 & 0,25 & 0,15 \\
I0 a 69 & 0,24 & 0,18 & 0,18 & 0,13 & 0,09 & 0,06 \\
\hline
\end{tabular}

Fonte: FIBGE, 1995. 
O cenário "pessimista", apresentado na tabela 5 corresponde a uma situação em que a velocidade de redução do analfabetismo entre dez e dezenove anos cai ao longo do tempo expressando uma "dificuldade" marginal crescente em sua eliminação. A hipótese de dificuldade crescente, que possui certo grau de realismo - já que as populações analfabetas residuais comporão grupos com características peculiares, como os de pessoas em situação de indigência, etc. - resultou na adoção de uma curva de redução do analfabetismo na primeira coorte com o comportamento de uma função exponencial do tipo $y=b m^{x}$, que considera 1990 como ano zero para definir os parâmetros da curva por regressão.

TABELA 6

CENÁRIO DE REDUÇÃO CONSTANTE

TAXAS DE ANALFABETISMO - PROJEÇÃO LINEAR- BRASIL 1980-2020

\begin{tabular}{cccccccc}
\hline IDADE & I980 & I990 & \multicolumn{1}{c}{ I99| } & 2000 & 2010 & 2020 \\
\hline I0 a 19 & 0,21 & 0,15 & 0,15 & 0,03 & - & - & \\
20 a 29 & 0,17 & 0,12 & 0,12 & 0,09 & 0,02 & - & \\
30 a 39 & 0,24 & 0,15 & 0,15 & 0,11 & 0,08 & 0,01 & \\
40 a 49 & 0,31 & 0,24 & 0,24 & 0,15 & 0,11 & 0,08 & \\
50 a 59 & 0,37 & 0,31 & 0,31 & 0,24 & 0,15 & 0,11 & \\
60 a 69 & 0,47 & 0,40 & 0,40 & 0,33 & 0,25 & 0,15 & \\
10 a 69 & 0,24 & 0,18 & 0,18 & 0,12 & 0,07 & 0,05 & \\
\hline
\end{tabular}

Fonte: FIBGE, 1995.

O cenário "otimista" é apresentado na tabela 6 e corresponde a uma melhora constante nas taxas de analfabetismo, cuja curva teria comportamento linear partindo de 1990 (ano zero) para estimação dos parâmetros por regressão, representando uma situação na qual a redução é constante. Um exemplo seria o caso em que, à medida que a alfabetização dos grupos residuais fosse se tornando mais difícil, houvesse, como compensação, um incremento de esforços.

Os resultados de ambos os cenários mostram que se os esforços de alfabetização limitarem-se apenas à população jovem, apenas em algum momento, após o ano de 2020, o Brasil alcançaria a Argentina de 1990 em termos de analfabetismo. As taxas em 1990 de países como Chile e Cuba seriam alcançadas entre 2010 e 2020, e as do Paraguai entre 2000 e 2010 . Para saber em que ponto no tempo o Brasil teria taxas equivalentes às taxas desses países seria necessário realizar exercício semelhante para eles. No entanto, como é razoável admitir que nesses países o analfabetismo também caminha para a redução, é possível afirmar que o encontro provavelmente não se dará na década de 2000.

Como a população mais velha dificilmente é atingida pelas políticas de educação atuais e tem uma taxa de superação do analfabetismo muito baixa, tem-se, como resultado, que uma parte considerável da população em idade ativa será ainda analfabeta até, pelo menos, 2020. Independentemente do cenário adotado (pois a projeção nas coortes mais velhas não depende das hipóteses sobre jovens utilizadas nos cenários), bem mais de 8\% da população 
com idades acima de quarenta anos será, no ano de 2020, analfabeta. No cenário de redução desacelerada, até meados da década de 2010 , a população entre dez a dezenove anos teria taxas acima da linha de 5\%. Trata-se de um nível ainda alto em termos comparativos internacionais e com impacto duradouro, já que se trata de população extremamente jovem. $\bigcirc$ analfabetismo entre os jovens, nessa situação, só poderia vir a ser eliminado em algum momento distante no tempo, após 2020.

No cenário de redução constante, o analfabetismo entre os jovens seria eliminado antes de 2010, mas a população como um todo permaneceria ainda com taxas relativamente altas de analfabetismo por uma ou duas décadas. Considerando que o nível educacional medido pelo indicador taxa de analfabetismo é extremamente elementar e que, por razões diversas, a necessidade de educação na população deve aumentar ao longo dos anos, mesmo o cenário "otimista" reforça a urgência, já destacada em diversos outros estudos, da melhoria da qualidade educacional da população.

A Constituição de 1988 exige, no artigo 214, a elaboração do Plano Nacional de Educação, visando à melhoria da qualidade de ensino e erradicação do analfabetismo no país. Essa exigência é reforçada pela Lei de Diretrizes e Bases da Educação Nacional - lei n. 9.394/ 96, que determina, no parágrafo primeiro do artigo 87, o prazo de dez anos para sua execução. Uma das prioridades do plano diz respeito à extensão da educação a grupos etários além das crianças:

A segunda prioridade consiste no resgate da dívida social acumulada, garantindo a educação fundamental a todos que não tiveram acesso a ela na idade adequada, ou que não lograram concluí-la. Essa meta incorpora, de forma ampliada, a determinação constitucional de erradicação do analfabetismo, entendendo que a alfabetização deve ser interpretada no seu sentido mais amplo, isto é, como domínio de instrumentos básicos da cultura letrada, das operações matemáticas elementares, da evolução histórica da sociedade humana, da diversidade do espaço físico e político mundial e da constituição da sociedade brasileira. Envolve, ainda, a formação do cidadão responsável e consciente de seus direitos. Essa prioridade está incorporada na questão da Educação de Jovens e Adultos, que merece uma atenção especial neste Plano Nacional de Educação. (Brasil, 1996)

Esta prioridade se traduz em meta específica do Plano Nacional de Educação que, uma vez cumprida, implica a total erradicação do analfabetismo em todas as faixas etárias antes do início da década de 2010, para a qual as tabelas 5 e 6 projetam taxas entre $7 \%$ e $9 \%$ :

I. Alfabetizar, em dez anos, toda a população assegurando a oferta de processo de escolarização, equivalente às quatro séries fundamentais do Ensino Fundamental organizado em etapas, para todos os jovens e adultos que não tiveram acesso a essa informação.

(...)

4. Estabelecer programa para assegurar que as escolas públicas de ensino fundamental e médio, localizadas em áreas caracterizadas por analfabetismo e baixa escolaridade, ofereçam programas de alfabetização e de ensino supletivo para jovens e adultos. (Brasil, 1996) 
Cumprir integralmente essas metas é uma tarefa extremamente difícil. Salvo mudanças radicais no panorama das políticas educacionais brasileiras, é provável que nem mesmo o prazo estabelecido de dez anos seja suficiente para aumentar de modo significativo a escolarização de toda a população adulta, o que reforça a urgência de medidas orientadas a esse grupo. Os cenários apresentados nas tabelas 5 e 6 mostram que se as melhorias na educação limitarem-se apenas à população mais jovem, o Brasil persistirá durante muito tempo com uma grande parte de sua população com níveis educacionais bastante reduzidos.

A extensão da educação a jovens e adultos, no entanto, pode alterar esse quadro. É evidente que educar jovens e adultos envolve esforços maiores do que os de educação de crianças, já que requer inclusive modificações na estrutura do sistema de ensino, voltado essencialmente a elas. Por isso, as estratégias de melhoria de nível educacional da população agem corretamente ao destinar parte de suas atenções às crianças. No caso do analfabetismo, por exemplo, um dos principais resultados de longo prazo dessas estratégias é o fim da "produção" de novas gerações de analfabetos. Todavia, o fato é que convivemos com um grande montante de pessoas que não tiveram o acesso adequado à educação no passado e que, obviamente, não podem ser beneficiadas de maneira direta pela priorização dada às crianças.

Para exemplificar o impacto da educação de jovens e adultos nos indicadores agregados de analfabetismo do Brasil, foi construído um terceiro cenário, no qual as taxas de superação do analfabetismo são modificadas para jovens e adultos jovens. Tal cenário se baseia no pressuposto de uma situação em que o restante da dívida social acumulada - garantindo a educação fundamental a todos que não tiveram acesso a ela na idade adequada - foi efetivamente tratado, como prioriza o Plano Nacional de Educação, mas admitindo uma certa tolerância quanto a seus resultados, especialmente no que diz respeito à população mais velha. Essa tolerância se traduz em um prazo mais longo para execução do plano (até 20। 0 ) e metas mais flexíveis: resultados atingidos para a população abaixo de 29 anos no fim do prazo estendido e nenhuma modificação na situação atual para população acima dessa idade. Para tanto, foram projetadas as taxas de analfabetismo no Brasil até o ano de 2020, com base nas seguintes hipóteses:

I até o ano 2000, eliminação completa do analfabetismo absoluto abaixo da idade de dezenove anos, estratégia mais adequada para garantir a erradicação do analfabetismo no prazo determinado do que a opção pelo adiamento da erradicação para a década seguinte.

2.aumento da taxa de superação do analfabetismo do grupo entre vinte e 29 anos para 50\% no ano 2000, com estabilização nesse patamar, hipótese que reconhece a maior dificuldade de se obter sucesso entre populações mais velhas.

3.manutenção das taxas de superação dos demais grupos etários nos níveis de 1980-1990, situação que assume hipoteticamente que melhorias significativas 
na alfabetização da população de mais de trinta anos de idade não podem ser realizadas, seja por limitação de recursos, deliberação das estratégias das políticas de educação, dificuldades intrínsecas à educação de adultos ou qualquer outra circunstância que impeça a modificação radical das condições atuais.

A proporção de manutenção das coortes da população analfabeta foi ajustada de modo a incorporar as hipóteses de queda nas taxas de mortalidade existentes nas projeções do IPEA utilizadas.

TABELA 7

CENÁRIO DE INCREMENTO NA ALFABETIZAÇÃO DOS JOVENS E ADULTOS JOVENS TAXAS DE ANALFABETISMO - BRASIL 1980-2020

\begin{tabular}{ccccccc}
\hline IDADE & 1980 & 1990 & $|99|$ & 2000 & 2010 & 2020 \\
\hline I0 a 19 & 0,21 & 0,15 & 0,15 & - & - & - \\
20 a 29 & 0,17 & 0,12 & 0,12 & 0,08 & - & - \\
30 a 39 & 0,24 & 0,15 & 0,15 & 0,06 & 0,04 & - \\
40 a 49 & 0,31 & 0,24 & 0,24 & 0,15 & 0,06 & 0,04 \\
50 a 59 & 0,37 & 0,31 & 0,31 & 0,24 & 0,15 & 0,06 \\
60 a 69 & 0,47 & 0,40 & 0,40 & 0,31 & 0,24 & 0,15 \\
I0 a 69 & 0,24 & 0,18 & 0,18 & 0,09 & 0,05 & 0,03 \\
\hline
\end{tabular}

Fonte: FIBGE, 1995

O cenário de incremento na alfabetização dos jovens e adultos jovens mostra que as taxas de analfabetismo no Brasil cairão a patamares similares aos de outros países da América do Sul já em 2010, caso as prioridades do Plano Nacional de Educação sejam seguidas, mesmo quando se considera que nem todas as metas propostas serão alcançadas. Pelas hipóteses mais tolerantes do cenário, o analfabetismo poderia ser considerado erradicado em meados da década de 2020. Cabe lembrar, no entanto, que as hipóteses do cenário, apesar de menos rigorosas do que as metas do Plano Nacional de Educação, são extremamente ambiciosas, pois dependem, em parte, da capacidade do Brasil antecipar, em uma década, a redução do analfabetismo nas idades abaixo de 29 anos, projetadas pelo cenário "otimista" de redução constante das taxas de analfabetismo, apresentado na tabela 6. As taxas de superação do analfabetismo assumidas no cenário de incremento na alfabetização dos jovens e adultos jovens são entre duas vezes maiores do que as observadas ao longo da década de 1980 para as idades entre dez e dezenove anos, e cerca de seis vezes maiores para as idades entre vinte e 29 anos.

\section{CONCLUSÕES}

A evolução de longo prazo do analfabetismo no Brasil mostra que as altas taxas de analfabetismo observadas hoje no país não estão relacionadas apenas à presença de 
analfabetos de gerações antigas na população. Além dos aspectos essencialmente relacionados à dinâmica demográfica, há também os relacionados à ineficiência do sistema educacional na determinação das taxas atuais. Em outras palavras, o analfabetismo hoje é resultado tanto da insuficiência quanto da demora na melhoria da alfabetização ao longo da segunda metade deste século.

Comparado a outros países não-desenvolvidos, o Brasil encontra-se em situação inferior no que diz respeito às taxas de analfabetismo. Na América Latina, teria taxas mais de quatro vezes maiores do que a vizinha Argentina, ocupando posição intermediária entre Equador e Bolívia. Não há evidências de que o início tardio da redução do analfabetismo no país seja o principal responsável por essa situação. A pirâmide etária da população analfabeta mostra que o analfabetismo não está limitado à população idosa, sendo também alto entre crianças, jovens e adultos. Com o envelhecimento e morte dos analfabetos idosos, é de se esperar alguma redução na taxas totais de analfabetismo. Essa redução, porém, seria menor do que a esperada, mesmo que o problema estivesse circunscrito meramente a uma questão de dinâmica demográfica, uma vez que as elevadas taxas entre os jovens garantem a reposição do estoque de analfabetos na população.

Mantidas as condições atuais que determinam as chances de um indivíduo superar o analfabetismo, é de se esperar, de acordo com ambos os cenários construídos para projetar a população analfabeta no futuro, que o Brasil permaneça, em relação a países vizinhos, com pelo menos uma década de atraso na queda das taxas totais. No cenário otimista o analfabetismo entre os jovens seria eliminado por volta de 2010. No pessimista, porém, isso só ocorreria depois de 2020. Quanto aos adultos acima de quarenta anos de idade, é de se esperar proporções de pelo menos 8\% de analfabetos na população em 2020.

Os cenários estão simulando o que ocorrerá com o perfil educacional básico da população brasileira. Como a simples alfabetização já pode ser, hoje, considerada insuficiente para atender às necessidades mínimas de educação de um indivíduo, é de se esperar que ser analfabeto daqui a uma ou duas décadas seja qualitativamente pior do que no momento. Analogamente, é possível afirmar que o peso do baixo nível educacional será muito mais grave no futuro. Não revertidas as condições de propagação da população com baixo nível educacional através das gerações, uma fração significativa da população se encontrará em uma situação de "pobreza educacional" nas próximas décadas.

A evolução dos grupos etários no tempo apenas propaga situações iniciais se essas não alterarem as condições que as geraram. Essas condições podem ser revertidas, rompendo os efeitos de inércia atualmente observados na população analfabeta. Isso sugere que as políticas de melhoria do nível educacional dos indivíduos não devem estar limitadas à população mais jovem, mas deve também englobar, pelo menos, populações com idades entre 20 e 29 anos na década de 1990 para que o Brasil possa alcançar nas primeiras décadas do próximo século patamares equivalentes aos de outros países da América do Sul. 
Os resultados das projeções sugerem que algumas das metas do Plano Nacional de Educação têm chances reduzidas de serem efetivamente alcançadas dentro dos limites de tempo estabelecidos. $\bigcirc$ terceiro cenário sugere que metas para a educação de jovens e adultos mais tolerantes, mas ainda assim extremamente ambiciosas, são difíceis de serem alcançadas antes de meados da década de 2020, mas que o Brasil já teria condições de se aproximar da condição de outros países sul-americanos de 1990 já na década de 2010 . Esses resultados, evidentemente, dependem da capacidade de se aumentar a educação de jovens e adultos já no curto prazo.

\section{REFERÊNCIAS BIBLIOGRÁFICAS}

BRASIL. Constituição da República Federativa do Brasil. 1988

BRASIL. Lei n. 9.394/96 de Diretrizes e Bases da Educação Nacional. 1996

FERRARI, A. R. Analfabetismo no Brasil: tendência secular e avanços recentes. Cadernos de Pesquisa. São Paulo. n.52, p.35-49, fev. 1985.

FIBGE. Anuário Estatístico 1995. 1995 (Versão em CD).

FIBGE. Pesquisa Nacional por Amostra de Domicílios - PNAD. Microdados 1996

PAIVA, V. Anos 90: as novas tarefas da educação de adultos na América Latina. Cadernos de Pesquisa. São Paulo. n.89, p.29-38, maio 1994.

ROCKWELL, E. Os Usos escolares da língua escrita. Cadernos de Pesquisa. São Paulo. n.52, p.85-95, fev. 1985.

SOARES, M. B. As Muitas facetas da alfabetização. Cadernos de Pesquisa. São Paulo. n.52, p. 19-24, fev. 1985.

UNESCO. Global Education Database. 1994. 


\section{APÊNDICE}

TABELA A-I

DISTRIBUIÇÃO ETÁRIA DA POPULAÇÃO ANALFABETA - BRASIL 1996

\begin{tabular}{lll}
\hline Idade & Homens & Mulheres \\
\hline 10 a 19 & 1578703 & 859316 \\
20 a 29 & 1148552 & 766794 \\
30 a 39 & 1202479 & 1125049 \\
40 a 49 & 1252502 & 1425273 \\
50 a 59 & 1166365 & 1532937 \\
\hline
\end{tabular}

Fonte: FIBGE, 1996

Valores utilizados nas projeções

TABELA A-2

PROPORÇÃO DA POPULAÇĀO DE UMA COORTE MANTIDA ATÉ A DÉCADA SEGUINTE - BRASIL 1980-2020

\begin{tabular}{ccccc}
\hline IDADE & $1980-1990$ & $1990-2000$ & $2000-2010$ & $2010-2020$ \\
\hline I0 a 19 & 0,92 & 0,93 & 0,97 & 0,98 \\
20 a 29 & 0,95 & 0,96 & 0,97 & 0,97 \\
30 a 39 & 0,97 & 0,96 & 0,96 & 0,96 \\
40 a 49 & 0,89 & 0,91 & 0,92 & 0,93 \\
50 a 59 & 0,86 & 0,86 & 0,87 & 0,89 \\
\hline
\end{tabular}

Fontes: FIBGE, 1995.

Nota: 1990 obtida por interpolação geométrica de 1980 e 1991.

Parâmetros da equação da reta de regressão utilizada na hipótese de redução linear das taxas de analfabetismo na primeira coorte

$$
y=-0,0617 x+0,212
$$

onde:

$y$ - taxa de analfabetismo

$x-$ ano, com $1990=0$

Parâmetros da equação da curva de regressão utilizada na hipótese de redução exponencial das taxas de analfabetismo na primeira coorte

$$
y=0,7092^{x}
$$

onde:

y - taxa de analfabetismo

$x-$ ano, $\operatorname{com} 1990=0$ 


\section{Estimativa da taxa de superação do analfabetismo}

A proporção da população total mantida na coorte $\left(P_{T M C}\right)$ entre uma década e outra calcula-se pela fórmula:

$$
\text { ।. } P_{T M C}=\frac{\sum_{i=a i+10}^{a f+10} \operatorname{Pop}_{i}(t+10)}{\sum_{i=a i}^{a f} \operatorname{Pop}_{i}(t)}
$$

onde:

$P_{\text {TMC }}$ - Proporção da População Total Mantida na Coorte;

Pop $(\mathrm{t})$ - População na idade i no ano t;

ai - Idade inicial da coorte;

af - Idade final da coorte;

$\mathrm{t}$ - Ano de referência;

A "saída natural de coorte" por mortalidade, migração ou qualquer outro motivo é o resultado da diferença entre os tamanhos de coorte entre uma década e outra. A expressão "natural" é utilizada apenas como termo antagônico à saída por "superação do analfabetimo". Assume-se que as proporções de saída "natural" da população analfabeta da coorte, ao longo da década $\left(P_{\text {SNAC }}\right)$, são as mesmas da população total $\left(P_{\text {TSC }}\right)$.

2. $\mathrm{P}_{\mathrm{TSC}}=1-\mathrm{P}_{\mathrm{TMC}}$

3. $P_{S N A C}=P_{T S C}$

4. $P_{S N A C}=1-\frac{\sum_{i=a i+10}^{a f+10} \operatorname{Pop}_{i}(t+10)}{\sum_{i=a i}^{a f} \operatorname{Pop}_{i}(t)}$

onde:

$P_{\text {SNAC }}$ - Proporção de Saída Natural da População Analfabeta da Coorte;

$\mathrm{P}_{\text {TSC }}$ - Proporção da População Total que Saiu da Coorte;

No modelo os analfabetos podem deixar a população ou pelos mesmos motivos que provocam a saída na população total ou pela superação do analfabetismo. A Proporção de Saída Total da População Analfabeta da Coorte $\left(P_{\text {STAC }}\right)$ é portanto igual à soma da Proporção de Saída Natural da População Analfabeta da Coorte $\left(P_{\text {SNAC }}\right)$ e da Proporção de Superação do Analfabetismo na Coorte $\left(\mathrm{P}_{\text {SupAC }}\right)$ :

$$
\begin{aligned}
& P_{S T A C}={ }^{P_{S N A C}}+\text { SupAC }= \\
& 5 \quad \frac{\sum_{i=a i+10}^{a f+10} \operatorname{Pop}_{i}(t+10)}{\sum_{i} \operatorname{Pop}_{i}(t)} \\
& \text { af }+10 \\
& 1-\frac{\sum_{i=a i+10} P_{0 p}-A_{i}(t+10)}{a f} \\
& \sum_{i=a i} \operatorname{Pop}_{i}-A_{i}(t)
\end{aligned}
$$


Pop $_{\llcorner} A(t)$ - População Analfabeta na idade i no ano t;

$\mathrm{P}_{\text {STAC }}$ - Proporção de Sá́da Total da População Analfabeta da Coorte;

$P_{\text {SupAC }}$ - Proporção de Superação do Analfabetismo na C oorte;

Define-se a população analfabeta esperada ao fim do período caso não houvesse superação como o produto da Proporção de Saída N atural da População Analfabeta da Coorte $\left(\mathrm{P}_{\mathrm{SNAC})}\right.$ pela população analfabeta no início do período.

6. $E\left(P_{\circ} \_A(t+10)\right)=P_{S N A C} \times P_{\left\llcorner O p_{\llcorner}\right.} A(t)$

A população que superou o analfabetismo (PopSupA), no final do período, é dada pelo resultado da diferença entre a população analfabeta esperada caso não houvesse superação e a população que se manteve analfabeta observada:

7. PopSupA $(t+10)=E\left(\operatorname{Pop}_{\llcorner} A(t+10)\right)-\operatorname{Pop}_{\llcorner} A(t+10)$

onde:

PopSupA - População que Superou o Analfabetismo

A razão entre a proporção da população analfabeta que superou o analfabetismo, ao longo do perío do, e a proporção da população analfabeta total, no início do perío do, é a taxa de superação do analfabetismo. $\mathrm{N}$ o caso de resultados negativos, as taxas de superação são tratadas como sendo iguais a zero.

8.

TaxaSUP $=\frac{\text { PopSupA }(\mathrm{t}+10)}{\text { Popi_A }(\mathrm{t})}$
onde:

Taxa $_{\text {Sup }}$ - Taxa de Superação do Analfabetismo;

\section{Populações utilizadas nos cenários}

TABELA A-3

POPULAÇÃO TOTAL O BSERVADA E PROJETADA - BRASIL 1980-2020

\begin{tabular}{rrrrrrr}
\hline IDADE & \multicolumn{1}{c}{1980} & \multicolumn{1}{c}{1990} & \multicolumn{1}{c}{1991} & \multicolumn{1}{c}{2000} & \multicolumn{1}{c}{2010} & \multicolumn{1}{c}{2020} \\
\hline 10 a 19 & 27.838 .937 & 31.653 .348 & 32.064 .631 & 34.108 .416 & 32.379 .320 & 30.910 .332 \\
20 a 29 & 20.955 .223 & 25.671 .643 & 26.202 .956 & 29.521 .971 & 33.085 .724 & 31.579 .387 \\
30 a 39 & 14.038 .968 & 19.830 .033 & 20.527 .256 & 24.662 .877 & 28.496 .309 & 32.030 .448 \\
40 a 49 & 10.377 .158 & 13.587 .817 & 13.959 .402 & 19.097 .535 & 23.629 .390 & 27.392 .989 \\
50 a 59 & 7.250 .034 & 9.186 .284 & 9.407 .252 & 12.356 .523 & 17.633 .956 & 21.956 .105 \\
60 a 69 & 4.474 .494 & 6.205 .855 & 6.412 .918 & 7.915 .940 & 10.800 .192 & 15.648 .656 \\
10 a 69 & 84.934 .814 & 106.134 .980 & 108.574 .415 & 127.663 .261 & 146.024 .891 & 159.517 .916 \\
\hline
\end{tabular}

Fontes: FIBGE, 1995.

N ota: 1990 obtida por interpolação geométrica de 1980 e 1991. 
TABELA A-4

POPULAÇÃO AN ALFABETA OBSERVADA E PROJETADA COM HIPÓTESE DE REDUÇÃO LINEAR DAS TAXAS DE AN ALFABETISMO NA PRIMEIRA COORTE - BRASIL 1980-2020

\begin{tabular}{lcrrrrr}
\hline IDADE & \multicolumn{1}{c}{1980} & \multicolumn{1}{c}{1990} & \multicolumn{1}{c}{1991} & \multicolumn{1}{c}{2000} & \multicolumn{1}{c}{2010} & \multicolumn{1}{c}{2020} \\
\hline 10 a 19 & 5.911 .818 & 4.767 .433 & 4.832 .565 & 925.217 & - & - \\
20 a 29 & 3.498 .110 & 3.190 .227 & 3.256 .646 & 2.572 .676 & 499.280 & - \\
30 a 39 & 3.369 .034 & 3.040 .650 & 3.148 .035 & 2.773 .030 & 2.236 .238 & 433.987 \\
40 a 49 & 3.193 .063 & 3.230 .325 & 3.318 .124 & 2.915 .461 & 2.658 .859 & 2.144 .168 \\
50 a 59 & 2.699 .136 & 2.887 .820 & 2.957 .814 & 2.921 .519 & 2.636 .755 & 2.404 .684 \\
60 a 69 & 2.113 .775 & 2.467 .197 & 2.548 .833 & 2.639 .667 & 2.670 .471 & 2.410 .177 \\
10 a 69 & 20.784 .936 & 19.583 .651 & 20.062 .017 & 14.747 .570 & 10.701 .604 & 7.393 .016 \\
\hline
\end{tabular}

Fontes: FIBGE, 1995.

N ota: População base 1990 obtida por interpolação geométrica de 1980 e 1991.

TABELA A-5

POPULAÇÃO AN ALFABETA OBSERVADA E PROJETADA COM HIPÓTESE DE REDUÇÃO EXPONENCIAL DAS TAXAS DE AN ALFABETISMO NA PRIMEIRA COORTE - BRASIL 1980-2020

\begin{tabular}{ccccccr}
\hline ID ADE & 1980 & 1990 & 1991 & \multicolumn{1}{c}{2000} & 2010 & \multicolumn{1}{c}{2020} \\
\hline 10 a 19 & 5.911 .818 & 4.767 .433 & 4.832 .565 & 2.584 .160 & 1.739 .891 & 1.178 .025 \\
20 a 29 & 3.498 .110 & 3.190 .227 & 3.256 .646 & 2.572 .676 & 1.394 .505 & 938.907 \\
30 a 39 & 3.369 .034 & 3.040 .650 & 3.148 .035 & 2.773 .030 & 2.236 .238 & 1.212 .141 \\
40 a 49 & 3.193 .063 & 3.230 .325 & 3.318 .124 & 2.915 .461 & 2.658 .859 & 2.144 .168 \\
50 a 59 & 2.699 .136 & 2.887 .820 & 2.957 .814 & 2.921 .519 & 2.636 .755 & 2.404 .684 \\
60 a 69 & 2.113 .775 & 2.467 .197 & 2.548 .833 & 2.639 .667 & 2.670 .471 & 2.410 .177 \\
10 a 69 & 20.784 .936 & 19.583 .651 & 20.062 .017 & 16.406 .514 & 13.336 .720 & 10.288 .102 \\
\hline
\end{tabular}

Fontes: FIBGE, 1995.

N ota: População base 1990 obtida por interpolação geométrica de 1980 e 1991.

TABELA A-6

POPULAÇÃO AN ALFABETA OBSERVADA E PROJETADA COM HIPÓTESE DE INCREMENTO NA ALFABETIZAÇÃO DOS JOVENS E ADULTOS JOVENS - BRASIL 1980-2020

\begin{tabular}{lrrrccc}
\hline \multicolumn{1}{c}{ ID ADE } & 1980 & 1990 & 1991 & 2000 & 2010 & 2020 \\
\hline 10 a 19 & 5.911 .818 & 4.767 .433 & 4.832 .565 & - & - & - \\
20 a 29 & 3.498 .110 & 3.190227 & 3.256 .646 & 2.223 .209 & - & - \\
30 a 39 & 3.369 .034 & 3.040 .650 & 3.148 .035 & 1.532 .434 & 1.072 .985 & - \\
40 a 49 & 3.193 .063 & 3.230 .325 & 3.318 .124 & 2.899 .049 & 1.453535 & 1.021 .126 \\
50 a 59 & 2.699 .136 & 2.887 .820 & 2.957 .814 & 2.937 .601 & 2.676 .874 & 1.350605 \\
60 a 69 & 2.113 .775 & 2.467 .197 & 2.548 .833 & 2.488 .471 & 2.567 .604 & 2.375 .501 \\
10 a 69 & 20.784 .936 & 19.583 .651 & 20.062 .017 & 12.080 .763 & 7.770 .998 & 4.747 .233 \\
\hline
\end{tabular}

Fontes: FIBGE, 1995.

N ota: População base 1990 obtida por interpolação geométrica de 1980 e 1991. 